\title{
Rancang Bangun Website Sistem Informasi Manajemen Rantai Pasok Distribusi Sepatu Lokal
}

\author{
Devinta Nurul Fitriana ${ }^{1}$, Niken Ayu Setifani ${ }^{2}$, Yusuf Amrozi ${ }^{3}$ \\ ${ }^{1,2,3}$ Sistem Informasi, Fakultas Sains dan Teknologi, UIN Sunan Ampel Surabaya, Surabaya, Indonesia \\ 1 devintafitriana28@gmail.com \\ ${ }^{2}$ nikenayustef@gmail.com \\ ${ }^{3}$ yusuf.amrozi@uinsby.ac.id
}

Diterima 28 Agustus 2020

Disetujui 18 November 2020

\begin{abstract}
Micro, small and medium enterprises (UMKM) in Indonesia is increasing every year. The increase in the number of UMKM has a significant impact on the Indonesian economy, so the government lowers the UMKM tax so that UMKM businesses develop rapidly. However, that does not make the other problems faced by the UMKM to be overcome. One problem that arises is the marketing and distribution of product results. The purpose of this research is to build a local shoe product distribution system based on a website to make it easier for resellers or shops to order shoes to the production. Processed data include retailer and store data, distributor data, product data, transaction data, and ordering data. Using the waterfall development model and using the Unified Modeling Language (UML) to visualize system modeling. This research generates reports of every activity carried out in the system including reports for factories, distributors and retailers.
\end{abstract}

Index Terms - distribution, information system, scm, website

\section{PENDAHULUAN}

Sekarang ini, sepatu bukan hanya sebagai alas kaki untuk kita beraktifitas diluar rumah. namun kini, sepatu sudah dianggap sebagai salah satu fashion item yang dapat menunjukkan standar hidup seseorang. Maka tidak heran jika para produsen sepatu saling berlomba-lomba mengeluarkan produk mereka masing-masing, untuk mewujudkan standar hidup kaum milenial saat ini. Berbagai model, warna dan motif yang beragam sangat memanjakan kita sebagai pembeli.

Ditengah gempuran sepatu produksi luar negeri dengan merk yang terkenal, sudah banyak industri lokal yang memproduksi sepatu juga. Usaha mikro kecil dan menengah (UMKM) yang pada tahun 2018 berkontribusi dalam pertumbuhan ekonomi Indonesia sebesar $60 \%$ ini, berkembang sangat signifikan setiap tahun[1]. Berbagai macam produk yang sudah dibuat dan dipasarkan oleh pelaku UMKM, diantara produkproduk tersebut ada produk sepatu. Merk sepatu lokal buatan anak negeri harus menghadapi pasar global yang tidak mudah dengan pesaing dari berbagai merk sepatu impor. Selain harus inovatif dan kreatif, produsen sepatu lokal harus pandai-pandai juga dalam hal pemasaran produk.

Manajemen rantai pasok merupakan suatu sistem yang dibuat untuk menyalurkan produk kepada konsumen akhir dengan mengimplementasikan teknologi informasi untuk memudahkan pengkoordinasian semua elemen rantai pasok, penghubung antara pabrik, distributor, pemasok dan pengecer. Dengan memperhatikan manajemen rantai pasok maka antara permintaan dan penawaran dapat diselaraskan, sehingga proses produksi dapat dilakukan secara efisien dan tepat sasaran. Selain itu, juga mengatur rantai pasok dapat meratakan dan mempermudah dalam pendistribusian produk.

Pada penelitian sebelumnya, proses pemasaran pada salah satu pelaku UMKM di Sruni Sidoarjo masalah yang ditemui adalah belum adanya SDM yang khusus menangani bidang pemasaran produk dan tidak memiliki media pemasaran yang tepat sehingga hanya mengandakan konsumen yang sudah pernah bertransaksi serta mendistribusikannya ke kolega dan pengepul yang dikenalnya saja. Padahal di zaman serba internet ini, seharusnya bisa dimanfaatkan untuk mempermudah produsen dalam memasarkan dan mendistribusikan produknya.

Untuk mengatasi masalah tersebut, dibutuhkan sebuah sistem informasi manajemen rantai pasok distribusi sepatu lokal yang dimana para reseller atau pemilik toko-toko sepatu tidak perlu datang langsung untuk mendaftar atau memesan produk sepatu yang diinginkan dan pihak perusahaan dapat memberi informasi mengenai tersedianya produk sepatu yang diproduksi. Sistem ini dibuat berupa website agar lebih mudah diakses dimanapun dan kapanpun tanpa harus mengunduh seperti aplikasi Android. 
Sistem informasi manajemen rantai pasok ini dibangun berbasis website dengan model pengembangan waterfall karena model ini sesuai untuk sebuah sistem yang sudah jelas kebutuhannya diawal. Produk sistem yang dikembangkan dengan model ini kebanyakan menghasilkan sistem berkualitas baik karena dimodel ini setiap fase yang ada harus dituntaskan sebelum melanjutkan ke fase berikutnya. Untuk menvisualisasikan pemodelannya digunakan Unified Modeling Language (UML). Untuk Mendapatkan pandangan mengenai sistem yang akan dibuat, UML menyediakan beberapa diagram visual yang mempresentasikan berbagai aspek didalam sistem. Berbagai diagram yang ada ditujukan untuk memberi gambaran yang lebih spesifik terhadap sistem informasi yang akan dibangun.

\section{LANDASAN TEORI}

\section{A. Website}

Website merupakan sekumpulan halamanhalaman yang terdapat pada domain internet dibuat dengan bertujuan tertentu agar saling berelasi sehungga bisa diakses secara luas melalui home page dan browser dengan menggunakan URL website. Unsur-unsur pada website ada 3 yaitu sebagai berikut:

\section{Domain}

Mudah diingat untuk pengguna internet nantinya ingin mengunjungi website tersebut kembali. Website itu ibarat produknya dan domain itu merknya. Apabila domain yang digunakan dapat menarik akan membuat pengguna internet tertarik memasuki website tersebut. Tentunya dengan pilihan nama domain yang berbeda dengan yang lain agar mudah diingat untuk pengguna internet nantinya ingin mengunjungi website tersebut kembali.

\section{Hosting}

Hosting berperan sebagai penyimpan semua database (gambar, script, teks, video dan sejenisnya) yang dibutuhkan dalam membangun sebuah website.

3. Konten

Konten dalam website bisa berupa gambar, teks dan video. Apabila dilihat dari segi konten yang diberikan, terdiri dari beberapa macam website. Misalnya website berita, sosial media, website yang berisi konten sesuai minat, website jual beli, hobi dan bakat[2].

Selain ketiga unsur diatas, pengembangan website juga sama seperti halnya aplikasi atau produk digital lain yaitu mempertimbangkan tampilan. Adanya UI dan atau user interface dalam pembuatan suatu produk digital dapat memudahkan developer dalam membangun produknya sebelum dilakukan pengkodean dan publish ke pengguna[3]. Warna, tata letak fitur dan button serta bebrapa unsur lain yang ada pada website harus di tata sedemikian rupa untuk memudahkan pengguna dalam pengoperasian website.

\section{B. MySQL}

MySQL merupakan database server yang memiliki fungsi untuk mengelola data sebelum ditransfer ke user. Oleh sebab itu pemrosesan terjadi di server, maka user bisa mengakses database kapan saja dan dimana saja dengan syarat komputer terhubung ke server[4].

\section{PHP}

PHP (Hypertext Preprocessor) merupakan bahasa scripting server-side yang digunakan untuk membuat website dinamis. PHP memiliki bebrapa kelebihan dibandingkan bahasa pemrograman yang lain, antara lain yaitu mudah dipelajari dan bisa berjalan pada sistem operasi apapun. PHP termasuk bahasa pemrograman yang populer karena memiliki fungsi built-in lengkap dan memiliki proses eksekusi yang cepat[5]. Server-side merupakan semua proses yang dilakukan pada server sebelum dikirimkan ke browser user. Maka hasil yang diterima oleh user yaitu berupa file yang berformat HTM[6].

\section{Manajemen Rantai Pasok}

Manajemen rantai pasok merupakan pengawasan dan pengelolaan mulai dari aliran barang mentah atau material, informasi pemasok ke produsen, pembayaran, pedagang grosir sampai pengecer ke konsumen. Rantai pasokan merupakan jaringan fisiknya, semua perusahaan yang memiliki peran dalam memasok bahan baku, produksi barang hingga mengirimkannya ke konsumen akhir. Manajemen Rantai Pasok merupakan sebuah metode, alat atau pendekatan pengelolaannya. Menurut James A dan Mona J. Fitzsimmons, Manajemen Rantai Pasok mrupakan suatu sistem pendekatan total guna untuk mengantarkan produk ke konsumen akhir dan teknologi informasi yang mengkoordinasikan semua elemen rantai pasokan mulai dari pemasok hingga ke pengecer.

Komponen-komponen manajemen rantai pasok sebagai berikut:

\section{1) Upstream Supply Chain}

USC yang mengatur relasi antara perusahaan dan vendor atau pihak lain pada proses transfer barang. Jadi, berbagai barang yang diproduksi oleh perusahaan tidak secara langsung sampai ke pihak konsumen akan tetapi disalurkan ke perusahaan perantara lainnya terlebih dahulu. Sebagai contoh, suatu perusahaan yang sedang produksi handphone. Produk handphone ini tidak sampai ke pihak konsumen secara langsung, akan 
tetapi pihak manufaktur yang akan mengirimkan produk tersebut kepada supllier.

\section{2) Downstream Supply Chain}

DSC yang memanajemen bagian transfer barang dari pihak perusahaan langsung ke pihak konsumen. Jadi, apabila USC harus melewati supplier terlebih dahulu, maka downstream langsung dapat dibeli oleh pihak konsumen. Sebagai contoh: manajemen dalam gallery art. Jadi, mereka akan membuat produk langsung berdasarkan kemauan pihak konsumen.

3) Internal Supply Chain

ISC yaitu yang berkaitan dengan aktivitas pemasokan barang. Pada hal ini yang harus diperhatikan adalah dari segi manajemen pabrikasi, kontrol ketersediaan bahan baku dan juga produksi[7].

\section{E. Unified Modelling Language}

UML merupakan sebuah cara permodelan secara visual sebagai sarana perancangan sistem yang berorientasi objek/sebagai bahasa yang telah menjadi standar dalam perancangan, visualisasi dan pendokumentasian sistem perangkat lunak.

Untuk mendapatkan berbagai pandangan terhadap sistem informasi yang akan dibuat, UML menyediakan beberapa diagram diantanya sebagai berikut:

\section{1) Use Case Diagram (UC)}

UC merupakan teknik dalam pengembangan sebuah sistem informasi guna untuk menangkap keperluan fungsional dari sebuah sistem yang bersangkutan.

\section{2)Activity Diagram ( $A D)$}

$\mathrm{AD}$ adalah aliran kerja dengan menggambarkan proses bisnis atau system.

\section{3) Conceptual Data Model (CDM)}

CDM merupakan rancangan database sesuai hasil analisis dan pengumpulan data..

\section{4)Physical Data Model (PDM)}

PDM merupakan rancangan basis data secara fisik dengan tipe datanya yang bersifat lebih khas dan spesifik dengan representasi dari database sebenarnya[8].

\section{Metode Penelitian}

Tahapan metode penelitian yang gunakan yaitu sebagai berikut:
1) Pengamatan proses bisnis Distributor Sepatu Lokal, yang bertujuan untuk mengetahui proses bisnis dari Distributor Sepatu Lokal.

2) Rancangan Spesifikasi Kebutuhan Perangkat Lunak (SKPL) guna untuk mendokumentasikan dan menganalisa kebutuhan pengguna pada website sistem informasi proses bisnis.

3) Merancang dan mengidentifikasi permasalahan pada proses bisnis dan Analisa perbaikan proses bisnis, kemudian melakukan perbandingan antara hasil. Pada tahapan ini menggunakan model waterfall, yaitu model klasik yang bersifat sistematis dan berurutan dalam membangun aplikasi atau sistem informasi. disebut dengan waterfall karena tahap demi tahap yang dilakukan harus menunggu selesainya tahap sebelumnya, sehingga harus berjalan secara berurutan.

Tahapan dalam Waterfall Model sebagai berikut:

a. Communication

Tahapan awal pada model waterfall yaitu komunikasi dengan customer untuk memahami dan mencapai tujuan yang ingin dicapai. Komunikasi menghasilkan inisialisasi proyek dengan mengumpulkan data-data yang dibutuhkan dan menganilisa permasalahan yang dihadapi.

b. Planning

Tahapan perencanaan menjelaskan tentang estimasi tugas-tugas teknis yang akan dilakukan, produk kerja yang ingin dihasilkan, resiko-resiko yang mungkin terjadi, penjadawalan kerja yang akan dilaksanakan, SDM yang diperlukan dalam membuat sistem, serta tracking proses pengerjaan sistem.

\section{c. Modeling}

Tahap perancangan yang berfokus pada perancangan struktur data, tampilan interface, arsitektur aplikasi dan algoritma program. Tujuannya untuk lebih memahami gambaran besar dari apa yang dikerjakan.

\section{d. Construction}

Tahap construction merupakan proses penerjemahan bentuk desain menjadi bentuk atau kode yang dapat dibaca oleh mesin. Kemudian dilakukan pengujian terhadap sistem dan juga kode yang sudah dibuat. Tujuannya agar menemukan kesalahan yang mungkin terjadi untuk nantinya diperbaiki.

\section{e. Deployment}

Tahap Deployment yaitu implementasi aplikasi ke customer, pemeliharaan aplikasi secara berkala, perbaikan aplikasi, evaluasi aplikasi, serta pengembangan aplikasi berdasarkan umpan 
balik yang diberikan agar sistem dapat tetap berjalan dan berkembang sesuai dengan kegunaannya[9].

\section{HASIL DAN PEMBAHASAN}

Pada penelitian ini, penulis menggunakan aplikasi Power Designer untuk membuat perancangan Use Case, Activity Diagram, CDM, PDM dan UI, sebagai berikut:

\section{A. Use case}

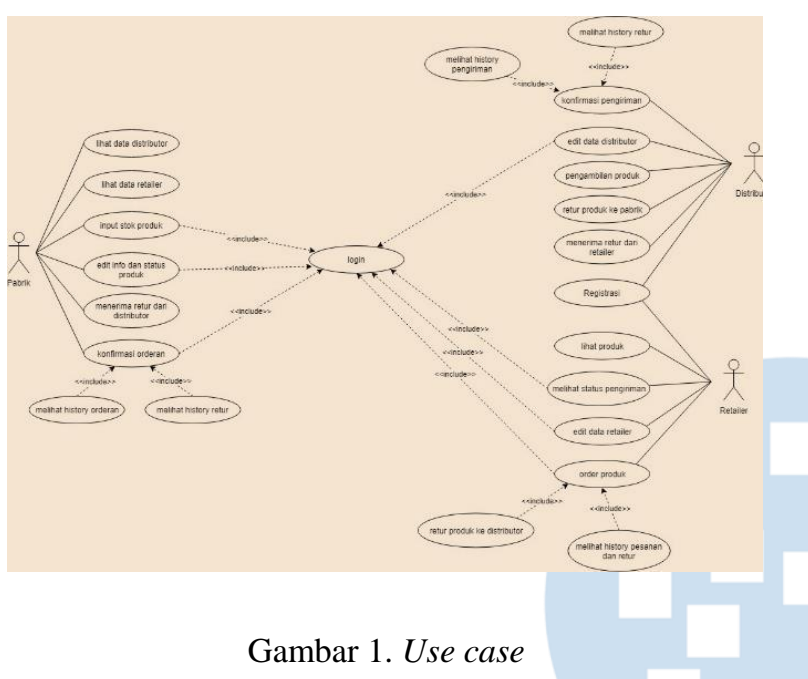

Pada Gambar 1, yaitu use case yang menjelaskan tentang jalannya system dalam rancangan tersebut, mulai dari Pabrik mengelola pendistribusian produk hingga pengiriman produk.

\section{B. Activity Diagram}

B.1 Activity

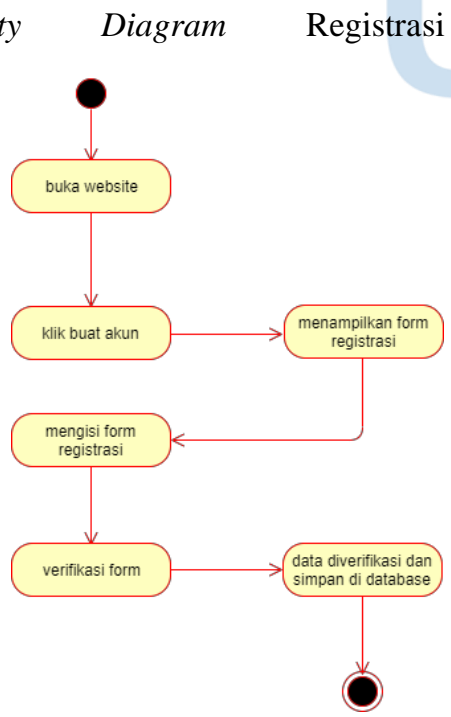

Pendaftar Sistem

Gambar 2. AD registrasi
Pada Gambar 2, merupakan Activity Diagram yang menjelaskan aliran kerja system dalam registrasi akun. Jadi, sebelum pengguna website diharuskan melakukan registrasi akun guna untuk disimpan dalam database dan menjaga akun tetap aman.

\section{B.2 Activity Diagram Login Pengguna Website}

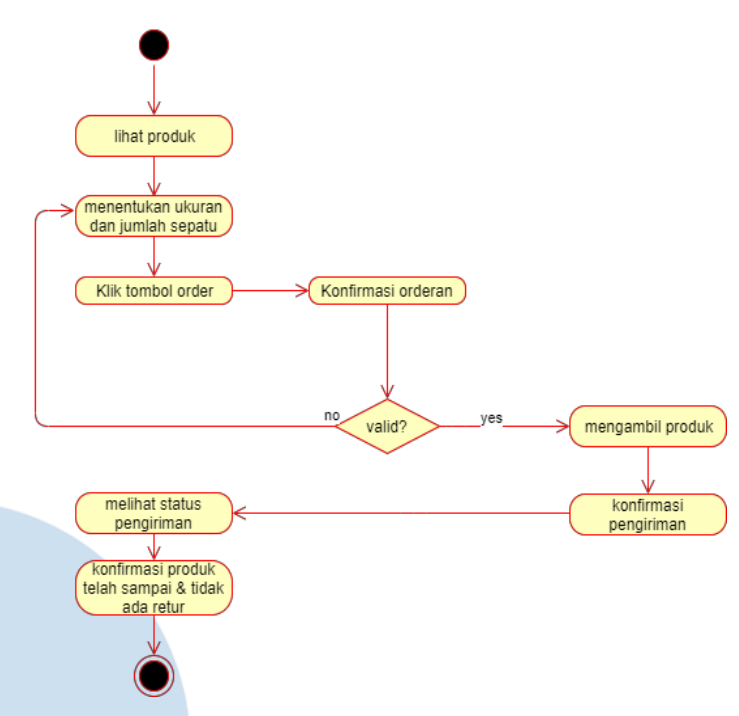

Gambar 3. AD login

Pada Gambar 3 Merupakan AD login. Sangat disarankan bagi pengguna website untuk melakukan login terlebih dahulu, supaya dapat melakukan aktivitas lainnya.

\section{B.3 Activity Diagram Pemesanan}

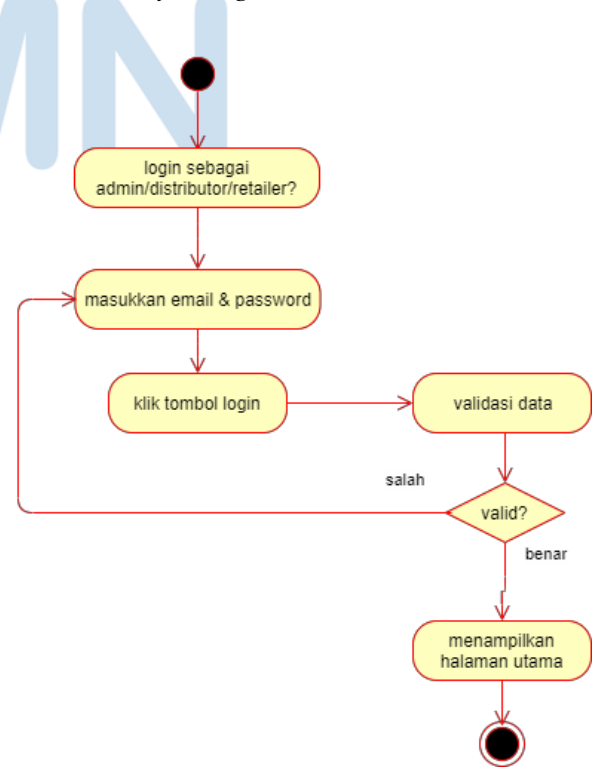


Pada Gambar 4 adalah activity diagram pemesanan. Dalam aktivitas ini semua actor ikut berperan, yaitu retailer melakukan pemesanan lalu pabrik konfirmasi pemesanan dan distributor mengambil barang ke pabrik, setelah itu dikirim ke retailer.

\section{B.4 Activity Diagram Retur Retail Distributor Pabrik}

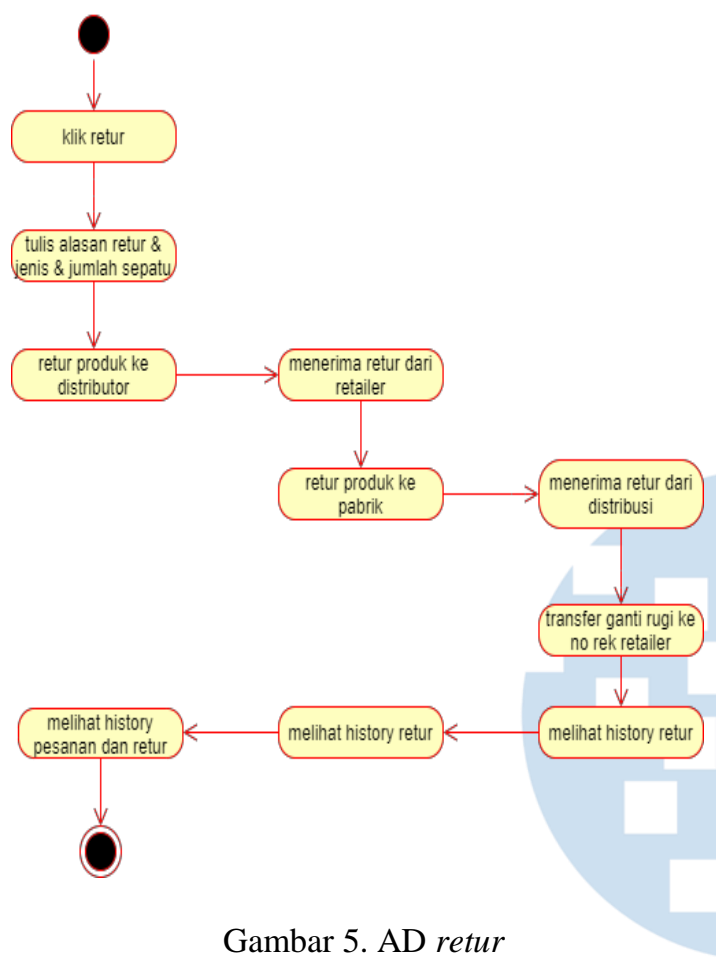

Pada Gambar 5 merupakan Activity Diagram yang menggambarkan aliran kerja retur dalam sistem. Jadi, maksud retur adalah apabila danya kerusakan produk yang diterima oleh retailer, maka retailer dapat mengirim retur ke distributor lalu retur diterima oleh pabrik. Ganti rugi yang diberikan pabrik kepada retailer adalah berupa uang yang ditransfer lewat bank.

\section{Conceptual Data Model}

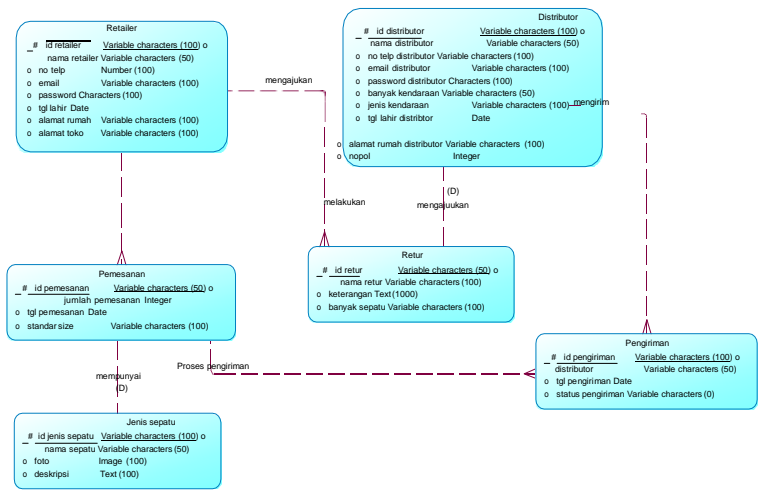

Gambar 6. CDM
Gambar 6 merupakan Conceptual Data Model dari sistem website distribusi sepatu guna untuk menyimpan data data para pengguna website. Mulai dari data distributor, data retailer, data pemesanan, data retur dan lain-lain.

\section{Physical Data Model}

Gambar 7 merupakan Physical Data Model yang sebenarnya sama saja seperti CDM, akan tetapi ini lebih ke fisiknya jadi lebih rinci dan jelas relasi anta entitas satu dengan yang lainnya.

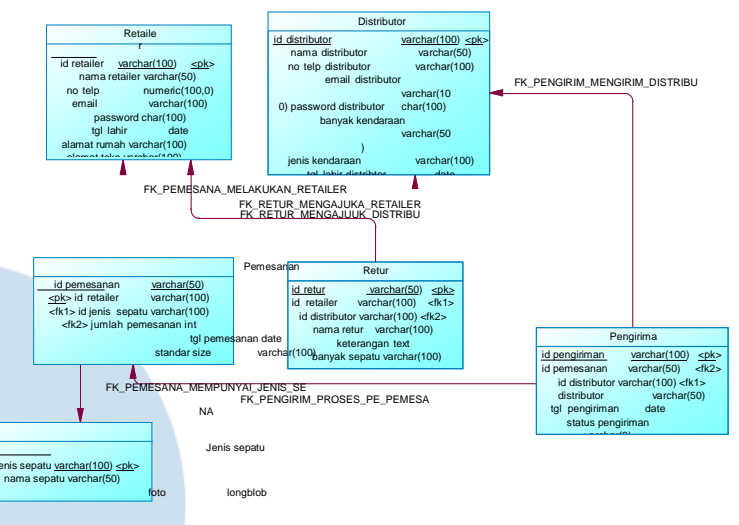

Gambar 7. PDM

E. User Interface

E.1 Halaman Website Secara Umum

Dihalaman ini ada beberapa menu diantaranya beranda, tentang kami untuk mengetahui profil dari UMKM, ada menu buat akun untuk registrasi distributor dan retailer, serta terdapat 3 login untuk user yaitu login admin (pabrik), login distributor, login retailer. Selain itu juga ada menampilkan produk-produk dan beberapa menu lain yang ada bagian bawah website.

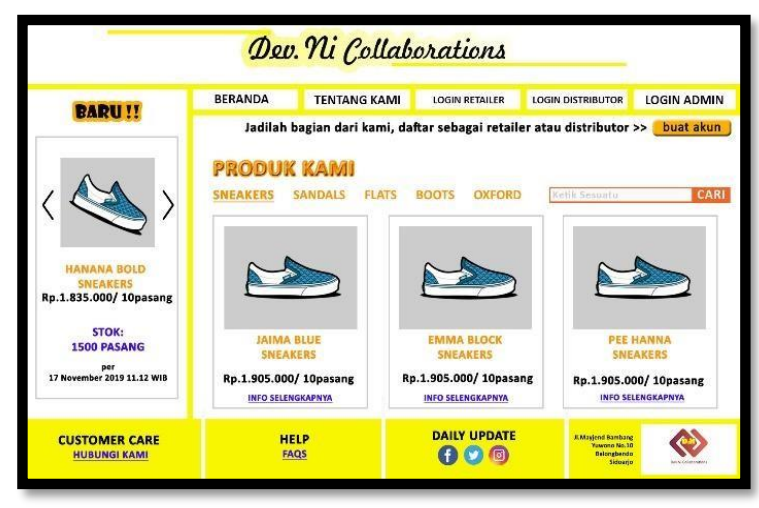

Gambar 8. Halaman utama website 


\section{E.2 Halaman Utama Admin}

Setelah login, admin akan diarahkan kehalamannya yang memiliki menu distributor untuk melihat data setiap distributor. Menu retailer untuk melihat data setiap retailer dan untuk konfirmasi retailer. Menu stok produk untuk mengedit dan melihat produk apa saja yang sudah diupload dan yang akan diupload. Menu retur untuk melihat permintaan retur serta terdapat history retur. Dan yang terakhir ada menu orderan yang digunakan untuk melihat progress orderan serta melihat history orderan. Selain itu ada button untuk menyimpan data sebagai PDF serta button keluar untuk keluar dari halaman admin.

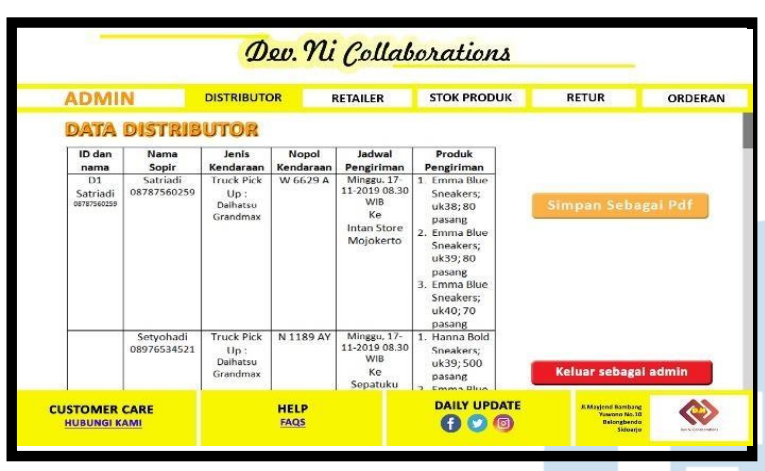

Gambar 9. Halaman utama admin

\section{E.3 Halaman Utama Distributor}

Halaman utama distributor berisi 3 menu utama. Menu jadwal pengiriman digunakan untuk melihat jadwal pengiriman yang akan datang serta informasi lebih lengkap mengenai detail pengiriman. Untuk menu retur ini berisi retur yang sudah diajukan ke pihak UMKM. Menu status pengiriman berisi status pengiriman ke pelanggan sampai proses apa barangnya dan dimenu ini juga terdapat history dari setiap pengiriman. Dibagian samping, terdapat profil dari distributor. Data-data yang tercantum bias diubah dengan menekan button edit data. Terdapat tombol keluar untuk distributor keluar dari halaman utama distributor. Saat keluar maka akan menampilkan halaman utama website seperti pada Gambar 8 .

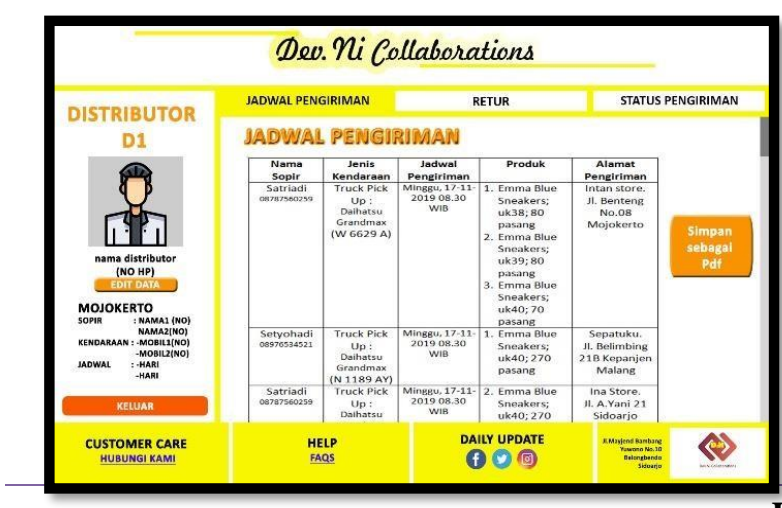

Gambar 10. Halaman utama distributor

\section{E.4 Halaman Utama Retailer}

Setelah login, retailer akan diarahkan ke halaman utama retailer. Terdapat 4 menu utama. Menu produk tersedia ini adalah katalog dari UMKM sepatu yang tersedia untuk dipesan ketika salah satu produk diklik maka akan menampilkan informasi lengkap mengenai produk serta terdapat tombol pesan. Menu order produk merupakan daftar produk yang telah dipesan. Dimenu retur merupakan menu untuk meminta retur atau pengembalian barang yang rusak setelah diisi maka barang bias dibawa kembali oleh distributor yang selanjutnya dibwa ke pabrik. Dan pihak pabrik akan mengkonfirmasi pengembalian dana juga masuk menu ini. Menu status pengiriman berisi data lengkap tentang pengiriman barang, seperti nama sopir, jenis kendaraan, sampai mana barang diproses dan informasi lain.

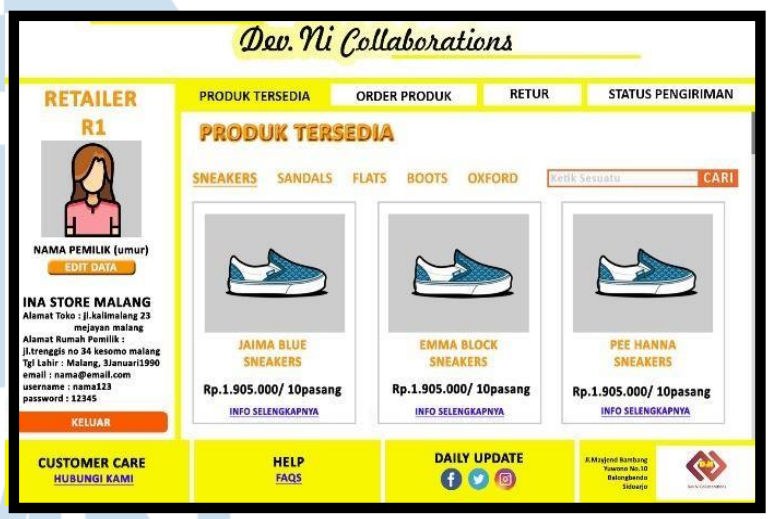

Gambar 11. Halaman utama retailer

\section{SIMPULAN}

Berdasarkan hasil perancangan website sistem informasi manajemen rantai pasok distribusi sepatu lokal, dapat disimpulkan sebagai berikut:

1. Sistem informasi manajemen rantai pasok yang dikembangkan dapat meningkatkan proses bisnis dengan sistem teknologi yang memberikan manfaat dalam menyimpan data agar lebih efisien dan efektif pada proses kerja pendistrbusian produk ke retailer serta dengan mudah menampilkan produk-produk yang bisa dipesan dan memudahkan kegiatan promosi.

2. Sistem informasi manajemen rantai pasok ini serta memudahkan dalam proses pembukuan sehingga tidak perlu melakukan pencatatan manual. Riwayat kegiatan transaksi bisa disimpan dalam bentuk berkas PDF sebagai laporan. 
Website ini belum sempurna dan masih harus dilakukan pengembangan lebih lanjut. Terdapat beberapa saran yang dapat dilakukan pada tahap pengembangan berikutnya, yaitu menambahkan fitur pembayaran produk secara non-tunai dan memberikan notifikasi aktivitas terbaru secara realtime.

\section{DAFTAR PUSTAKA}

[1] F. Hidranto, "DAMPAK COVID-19: Stimulus untuk UMKM," Indonesia.go.id, 2020.

[2] L. Anatan and L. Ellitan, SUPPLY CHAIN MANAGEMENT: Teori dan Aplikasi. Bandung: Alfabeta Bandung, 2008.

[3] M. D. Ariawan, A. Triayudi, and I. D. Sholihati, "Perancangan User Interface Design dan User Experience Mobile Responsive Pada Website Perusahaan," J. Media Inform. Budidarma, vol. 4, no. 1, p. 161, 2020, doi: 10.30865/mib.v4i1.1896.

[4] S. Haris, Manajemen Database MySQL menggunakan MySQL Front. Jakarta: Elex Media Komputindo, 2003.

[5] A. Wibowo, 16 Aplikasi PHP Gratis untuk Pengembangan Situs Web. Yogyakarta: ANDI, 2007.

[6] V. Lusiana, "Sistem Informasi Promosi Batik Tradisional Semarang Berbasis Web," J. Din. Inform., vol. 1, no. 1, pp. 26-35, 2009.

[7] I. N. Pujawan, Supply Chain Management, Pertama. Surabaya: Penerbit Guna Widya, 2005.

[8] Samsoni, "Perancangan Sistem Informasi Kontrol Produksi Sepatu (Studi Kasus: PT. Asia Dwimitra Industri Tangerang)," J. Inform. Univ. Pamulang, vol. 2, no. 3, pp. 153-158, 2017, [Online]. Available: http://openjournal.unpam.ac.id/index.php/informatika/article/vi ew/1445/pdf.

[9] R. S. Pressman, Rekayasa Perangkat Lunak: Pendekatan Praktisi Buku I. Yogyakarta: ANDI, 2015. 